\title{
DO ADOLESCENTS WITH T1DM DIFFER FROM THEIR PEERS IN HEALTH, EATING HABITS AND SOCIAL SUPPORT?
}

\author{
Daniela Husárová1, Michaela Kostičová2, Denisa Kočišová3 ${ }^{3}$ Ingrid Schusterováa ${ }^{3}$ Andrea Madarasová Gecková1,4 \\ 'Department of Health Psychology, Faculty of Medicine, Pavol Jozef Šafárik University in Košice, Košice, Slovak Republic \\ ${ }^{2}$ nsstitute of Social Medicine and Medical Ethics, Faculty of Medicine, Comenius University in Bratislava, Bratislava, Slovak Republic \\ ${ }^{3}$ Department of Paediatrics and Adolescent Medicine, Faculty of Medicine, Pavol Jozef Šafárik University in Košice, Košice, Slovak Republic \\ ${ }^{4}$ Olomouc University Social Health Institute, Palacký University Olomouc, Olomouc, Czech Republic
}

\section{SUMMARY}

Objective: The aim of this study was to analyse differences in health, eating habits and social support in adolescents with type 1 diabetes mellitus (T1DM) in comparison to peers with another long-term illness or without any medical condition.

Methods: We used self-reported data from the cross-sectional Health Behaviour in School-aged Children study collected in 2014 among Slovak adolescents as well as data from adolescents with T1DM collected in outpatient settings (11 to 15 years old, N=8,910, 50.3\% of boys). Logistic regression models and general linear models were used to analyse differences between adolescents with T1DM and their peers with and without long-term illness in self-rated health, life satisfaction, health complaints, regular breakfast, sweets and soft drink consumption, and perceived support from family, teachers and classmates.

Results: Adolescents with T1DM reported worse self-rated health and suffer from more health complaints, but they have lower chance of having breakfast irregularly in comparison to their peers with another long-term illness or without any medical condition. Moreover, compared with their peers, adolescents with T1DM perceived stronger support from teachers and classmates, but weaker support from their family. We did not confirm any differences in life satisfaction, sweets and soft drink consumption between adolescents with T1DM and their peers.

Conclusions: Adolescents with T1DM reported more regular eating habits, no difference in life satisfaction and more social support outside the family in comparison to their peers. However, their worse self-rated health, more health complaints and weaker support from family should be considered in interventions targeting psychosocial adjustment of adolescents with T1DM.

Key words: diabetes mellitus, adolescence, health, eating habits, social support

Address for correspondence: D. Husárová, Department of Health Psychology, Faculty of Medicine, P. J. Šafárik University in Košice, Trieda SNP 1, 04001 Košice, Slovak Republic. E-mail: daniela.husarova@upjs.sk

https://doi.org/10.21101/cejph.a4876

\section{INTRODUCTION}

Diabetes mellitus is one of the most common chronic diseases in adolescents (1), and the incidence is increasing in many countries worldwide, particularly in children under the age of 15 years (2-4). According to the International Diabetes Federation (IDF) Diabetes Atlas (4), in 2015 the number of children with type 1 diabetes mellitus (T1DM) exceeded half a million in the world for the first time, and the overall annual increase is estimated to be around 3\%. In Slovakia, the incidence has varied between 13 and 17 cases per 100,000 children aged 0-14 years since 2004 (5).

Nutritional management is the most important part of the complex management of T1DM. Dietary guidelines for T1DM stress the importance of regularity in meal time and adequate nutritional composition for better glycaemic outcomes $(2,6)$. However, several recent studies found that adolescents, also in Slovakia, often struggle with adherence to dietary recommendations, eat irregularly and do not follow a healthy diet $(5,7-9)$.
This poorer adherence may be associated with poor parent-child mealtime behaviours (7). A routine in which a child and family sit down and eat together helps to establish better eating practices, as is stressed in the IDF (3) guidelines.

The complex management of T1DM requires significant lifestyle changes, which remain a substantial burden on adolescents and their families $(1,6,10-12)$. Family factors and relations at school and with peers are integral for management of T1DM in children and adolescents $(3,13)$. Research has shown that high family support and good peer relations are associated with better adherence of adolescents to diabetes regimen and better glycaemic control $(13,14)$. However, as pointed out by Malik and Koot (12), behaviour viewed as supportive by the provider may have a negative effect on the receiver, depending on adolescents' perception of the supportiveness of specific behaviours. Thus, crucial for successful management of T1DM is that a family should provide a developmentally appropriate level of emotional support to children (10). The role of peers and teachers in management of T1DM in adolescence is also evident. According to Helgeson and 
Palladino (15), peers mainly provide diabetes-related emotional support, and peer conflict has a negative impact on diabetes outcomes. When adolescents perceive teachers' support and understanding of diabetes management, this might have a positive effect on their own self-management tasks during school attendance, as was found in the study of Hillard et al. (16).

In adolescence, young people are struggling for independence from their family, worrying about gaining acceptance from their peers and developing a sense of identity and self-esteem, all factors that affect their health-related behaviour $(6,14)$. Adolescents with T1DM believe they are self-responsible for diabetes tasks, which might lead to parental distress and family conflicts, with a negative impact on the management of T1DM (17-19). Several studies have found that bad glycaemic control is associated with a lower quality of life of adolescents with $\operatorname{T1DM}(11,20)$ and family diabetes-specific conflicts correlated with these negative outcomes (21).

Even though the population of adolescents with a long-term illness has increased, we still know little about the impact of chronic diseases on the functioning of young people. Identifying differences between adolescents with a specific health condition and their healthy peers might help to understand the mechanisms and needs they might have. Therefore, the aim of our study was to analyse differences in health outcomes (self-rated health, life satisfaction, health complaints), eating behaviour (breakfast consumption, sweets and soft drinks consumption), and perceived social support (from family, peers and teachers) between three groups of children (children with diabetes mellitus type 1, children with a long-term illness and children without any medical condition).

\section{MATERIALS AND METHODS}

\section{Sample and Procedure}

We used data from the Health Behaviour in School-aged Children (HBSC) study conducted in Slovakia in 2014. To obtain a representative sample, we used two-step sampling. In the first step, 151 larger and smaller elementary schools located in rural as well as urban areas from all regions of Slovakia were asked to participate. These were randomly selected from a list of all eligible schools in Slovakia obtained from the Slovak Institute of Information and Prognoses of Education. In the end, 130 schools agreed to participate in our survey (response rate $86.1 \%$ ). In the second step, we obtained data from 10,179 adolescents from the 5 th to the 9 th grades (response rate $78.8 \%$ ). After excluding children under 11 and over 15 years of age the sample comprised 8,883 respondents. We enriched this sample by collecting data from 27 adolescents of the same age with diabetes mellitus type 1 who regularly attend diabetic outpatient settings and filled in the reduced version of the HBSC questionnaires. Therefore, our final sample consisted of 8,910 adolescents (mean age 13.48 years, $50.3 \%$ of boys).

The study was approved by the Ethics Committee of Medical Faculty at P. J. Šafárik University in Košice. Parents were informed about the study via the school administration and could opt out if they disagreed with their child's participation. Participation in the study was fully voluntary and anonymous, with no explicit incentives provided for participation. Self-reported questionnaires were administered by trained research assistants in the absence of a teacher during regular class time and a trained diabetic nurse in outpatient settings.

\section{Measures}

Self-rated health was measured using the question: "Would you say that your health is: excellent, good, fair or bad" and was dichotomized into two categories: excellent or good health, fair or bad health.

Life satisfaction was assessed by a one-item scale where participants rank their life satisfaction on an 11-point scale ranging from 10 (best life possible) to 0 (worst life possible). The children were given the following instruction: "Here is a picture of a ladder. The top of the ladder (10) is the best possible life for you, and the bottom (0) is the worst possible life for you. In general, where on the ladder do you feel you stand at the moment?" The response categories were dichotomized using a cut-off at 6 to obtain two groups of children - those who indicated high and low life satisfaction.

The HBSC-symptoms checklist (HBSC-SCL) assessed the occurrence of eight subjective physical and psychological health complaints; namely headache, stomach ache, back ache, feeling low, irritability and bad temper, feeling nervous, sleeping difficulties, and feeling dizzy. The response categories indicating how frequently during the last 6 months the symptom occurred are "rarely or never", "about every month", "about every week", "more than once a week", and "about every day". Responses for specific health complaints were dichotomized ("rarely or never" and "about every month" vs. "about every week", "more than once a week" and "about every day"). Also, recurrent multiple health complaints were computed and subsequently dichotomized with two or more complaints at least once a week considered as displaying noticeable subjective health complaints $(22,23)$.

Breakfast consumption was measured by an item: "How often do you usually have breakfast during weekdays (more than a glass of milk or fruit juice)?" Responses were: "I never have breakfast during a week", "one day", "two days", "three days", "four days", and "five days". Having breakfast 5 days a week was categorised as "regular breakfast on weekdays" (24).

Sweets and soft drinks consumption were assessed by a question asking children how many times a week they usually eat sweets as well as drink coke or other soft drinks that contain sugar. Possible responses were: "never", "less than once a week", "once a week", "2-4 days a week", "5-6 days a week", "once a day, every day", "every day, more than once". To obtain two groups of adolescents - those who drink soft drinks or eat sweets once a day or more and the others - we dichotomized the responses.

Social support from family was measured using the Perceived Social Support Scale (25), which is a 12-item self-reported questionnaire assessing perceived social support in three dimensions (from family, friends and significant others). We only used the family dimension, which consists of four items: perceived help (my family really tries to help me), help with decision-making (my family helps me in decision-making), perceived emotional support from the family (my family gives me the emotional support and help I need), and talking about problems with the family (I can talk about my problems with my family). A 7-point Likert-type format was used ranging from "totally disagree" to "totally agree". 
The range of sum scores was 4-28, with a higher score indicating a higher level of perceived social support from the family (26).

The teacher and classmate support were assessed by eight items. Four of them refer to perceptions of support from teachers, and four of the items refer to support from classmates. Typical statements were "Other students accept me as I am" and "When I need extra help I can get it." Statements were rated on a 5-point Likert-type agreement scale, ranging from "strongly agree" to "strongly disagree". To allow a high score to reflect high support, all item scores were reversed prior to analysis (27). An increasing score indicated a higher level of perceived social support from teachers and classmates.

Long-term illness prevalence was assessed using the item: "Do you have a long-term illness, disability or medical condition (like diabetes, arthritis, allergy or cerebral palsy) that has been diagnosed by a doctor?" with "yes" and "no" as the response categories (28). The response used in statistical analyses referred to the occurrence of a long-term illness. Besides this question, we asked adolescents if they have diabetes mellitus confirmed by a doctor.

\section{Statistical Analysis}

In the first step descriptive statistics were used for the studied variables. Next, the associations of the presence of long-term illness or diabetes mellitus with self-rated health, life satisfaction, health complaints, breakfast consumption as well as sweets and soft drink consumption were analysed using a binary logistic regression model. Children without any long-term illness were used as the reference group. Moreover, interaction of the association of age, gender and the presence of long-term illness and diabetes mellitus on health and eating habits were subsequently explored. Finally, to compare adolescents without any long-term illness, with other long-term illness and with diabetes mellitus regarding social support, including family, classmate and teachers, we compared the means and proportions, depending on the measurement scales. The differences were tested using general linear models and then post-hoc computed to determine which means differ significantly. All analyses were performed using SPSS version 21.0.

\section{RESULTS}

Fair or poor health was reported by $18 \%$ of adolescents with a long-term illness and by almost $20 \%$ of adolescents with diabetes mellitus. Low satisfaction was reported by more than $20 \%$ of adolescents with a long-term illness and almost $24 \%$ of adolescents with a diabetes mellitus. Around half of adolescents do not eat breakfast regularly on school days and similar percentages were noted in case of adolescents with a long-term illness (46.9\%) as well as in adolescents with diabetes mellitus (34.0\%). Moreover, around $33 \%$ of adolescents with diabetes mellitus consume soft drinks on daily basis and $21 \%$ of them even consume sweets (Table 1).

Adolescents with T1DM have a higher chance of reporting fair or poor health and at least two health complaints at least once a week than do adolescents without any long-term illness; however, they have a two-times lower chance of reporting not having breakfast every school day. Similar findings were confirmed by comparison of adolescents with long-term illness with their peers without any long-term illness. Adolescents with a long-term illness have a two-times higher chance of reporting fair or poor health, low life satisfaction and at least two health complaints almost once a week in comparison to adolescents without any long-term illness. They also have a lower chance of reporting not having breakfast every school day. As for sweets and soft drink consumption, no significant differences were found (Table 2 ). The interactions of gender or age with long-term illness on self-rated health, health complaints, regular breakfast, sweets and soft drinks consumption were not significant. The exception was the interaction of gender with the presence of a long-term illness on low life satisfaction (not shown). While girls with T1DM are less satisfied in comparison with healthy girls, boys with T1DM are more satisfied than their healthy peers.

Table 3 shows the differences between three groups of adolescents in family, classmates and teachers' support. Adolescents with T1DM have the highest score in perceived support from their teachers and classmates. However, in case of family support, healthy adolescents have the highest score. Results from the general linear model suggest that healthy adolescents and

Table 1. Descriptive characteristics of the sample (Slovakia 2014, 11-15 years old, $N=8,910$ )

\begin{tabular}{|l|l|c|c|c|}
\hline \multirow{2}{*}{} & & $\begin{array}{c}\text { Without any long-term } \\
\text { illness } \\
\mathbf{N}(\%)\end{array}$ & $\begin{array}{c}\text { With a long-term illness } \\
\text { N (\%) }\end{array}$ & $\begin{array}{c}\text { With type 1 DM } \\
\text { N (\%) }\end{array}$ \\
\hline Total sample & & $7,053(79.2)$ & $1,759(19.7)$ & $98(1.1)$ \\
\hline \multirow{2}{*}{ Gender } & Boys & $3,587(50.9)$ & $836(47.5)$ & $58(59.2)$ \\
\cline { 2 - 5 } & Girls & $3,466(49.1)$ & $923(52.5)$ & $40(40.8)$ \\
\hline \multirow{2}{*}{ Age } & $11-12$ years old & $2,714(38.5)$ & $672(38.2)$ & $33(33.7)$ \\
\cline { 2 - 5 } & $13-15$ years old & $4,339(61.5)$ & $1,087(61.8)$ & $65(66.3)$ \\
\hline Self-rated health & fair or poor & $642(9.2)$ & $316(18.1)$ & $19(19.8)$ \\
\hline Life satisfaction & low & $1,194(17.2)$ & $375(21.5)$ & $22(23.7)$ \\
\hline Health complaints & $\geq 2$ symptoms at least once a week & $3,634(51.5)$ & $1,046(59.5)$ & $60(61.2)$ \\
\hline Breakfast consumption & less than every school day & $3,496(50.5)$ & $814(46.9)$ & $33(34.0)$ \\
\hline Sweets consumption & every day & $2,428(36.0)$ & $608(35.8)$ & $30(32.6)$ \\
\hline Soft drinks consumption & every day & $1,761(25.7)$ & $411(23.9)$ & $20(21.5)$ \\
\hline
\end{tabular}


Table 2. Differences in health outcomes and eating habits between children with diabetes mellitus, a long-term illness and without any long-term illness: logistic regression (Slovakia 2014, 11-15 years old, N=8,910)

\begin{tabular}{|l|c|c|c|}
\hline & $\begin{array}{c}\text { Without any long-term illness } \\
\text { OR (95\% CI) }\end{array}$ & $\begin{array}{c}\text { With a long-term illness } \\
\text { OR (95\% CI) }\end{array}$ & $\begin{array}{c}\text { With diabetes mellitus } \\
\text { OR (95\% CI) }\end{array}$ \\
\hline Self-rated health (fair or poor) & 1 & ${ }^{* * *} 2.16(1.87-2.51)$ & ${ }^{* * *} 2.48(1.49-4.13)$ \\
\hline Life satisfaction (low, score 0-5) & 1 & ${ }^{* * *} 1.31(1.15-1.49)$ & $1.52(0.94-2.47)$ \\
\hline Health complaints ( $\geq 2$ symptoms at least once a week) & 1 & ${ }^{* * *} 1.37(1.22-1.53)$ & ${ }^{* *} 1.88(1.18-2.98)$ \\
\hline Breakfast consumption (less than every school day) & 1 & ${ }^{* *} 0.56(0.77-0.95)$ & ${ }^{* *} 0.51(0.33-0.77)$ \\
\hline Sweets consumption (every day) & 1 & $0.98(0.88-1.09)$ & $0.87(0.56-1.35)$ \\
\hline Soft drinks consumption (every day) & 1 & $0.91(0.81-1.03)$ & $0.77(0.47-1.26)$ \\
\hline
\end{tabular}

${ }^{*} p<0.05 ;{ }^{* *} p<0.01 ;{ }^{* * *} p<0.001$

Table 3. Differences in perceived social support between children with diabetes mellitus, a long-term illness and without any long-term illness: general linear model (Slovakia 2014, $11-15$ years old, $N=8,910$ )

\begin{tabular}{|l|c|c|c|c|}
\hline & $\begin{array}{c}\text { Without any long-term } \\
\text { illness } \\
\text { M (SD) }\end{array}$ & $\begin{array}{c}\text { With a long-term illness } \\
\text { M (SD) }\end{array}$ & $\begin{array}{c}\text { With diabetes mellitus } \\
\text { M (SD) }\end{array}$ & Post hoc \\
\hline Family support & $24.51(4.78)$ & $24.30(4.90)$ & $22.88(6.85)$ & $1-3^{* *}, 2-3^{*}$ \\
\hline Classmate support & $11.25(2.39)$ & $11.01(2.39)$ & $11.82(2.61)$ & $1-2^{* *}, 2-3^{* *}$ \\
\hline Teacher support & $10.68(2.77)$ & $10.68(2.81)$ & $11.59(2.93)$ & $1-3^{* *}, 2-3^{* *}$ \\
\hline
\end{tabular}

${ }^{*} p<0.05 ;{ }^{* *} p<0.01 ;{ }^{* * *} p<0.001$

A higher score indicates higher family, classmate or teacher support.

adolescents with a long-term illness perceive higher support from the family in comparison to adolescents with T1DM. On the other hand, adolescents with T1DM perceive higher support from classmates and teachers in comparison to others. Moreover, adolescents with a long-term illness report significantly lower support from their classmates. The interaction of gender and age on associations of the presence of diabetes mellitus and long-term illness with perceived social support, including family, classmates and teachers, are not significant (not shown).

\section{DISCUSSION}

Our objective was to analyse differences in health outcomes, eating behaviour and perceived social support between adolescents with T1DM and their peers with a long-term illness and adolescents without any medical condition. We found that there are significant differences in self-rated health, life satisfaction, health complaints and breakfast consumption between adolescents with diabetes mellitus and their peers. Moreover, these adolescents differed in perceived social support, including family, peers and teachers.

Our results showed that adolescents with T1DM reported worse health and more health complaints than adolescents with a longterm illness or without any medical condition. These findings were supported by the study of deWitt et al. (29), who found that adolescents with T1DM reported worse general health as well as lower physical well-being that influence their daily functioning in school or in leisure time. Moreover, adolescents with a long-term illness reported lower life satisfaction in comparison with healthy peers. Recent research suggests that living with a chronic condition might be related to higher risk for psychological well-being, and children might feel more frequently sad, nervous or irritated (30). More psychosocial problems and lower health-related quality of life in children and adolescents with T1DM compared to their healthy peers were also found in another recent study (31). The results from a systematic review (32) revealed that generic quality of life of adolescents with diabetes mellitus is not impaired compared to healthy peers; however, disease-specific quality of life problems, including a negative impact of diabetes on daily functioning as well as diabetes-related worries were certainly present. The study of Berntsson et al. (33) concluded that adolescents with a long-term illness or disabilities experienced well-being when they were allowed to prepare for living a normal life integrated into society and when they felt support.

Adolescents with a long-term illness and T1DM in particular had a lower chance of having breakfast irregularly. On the other hand, daily consumption of sweets and soft drinks was high and was very similar among their healthy peers. Our findings are partially supported by the study of Nansel et al. (8), in which children with diabetes mellitus reported lower adherence to dietary guidelines, such as low fruit and vegetables intake or high saturated fat consumption. Similarly, Mehta et al. (9) suggested that consuming high-fat and low-fibre diets in adolescents with T1DM is comparable with youth in the general population. However, the study of Due et al. (34) found that more adolescents with T1DM reported healthy eating behaviour compared to national norms, particularly the prevalence of soft drinks and sweets use was significantly lower and the prevalence of daily breakfast higher compared to the general population. Regularity in meal times and routines in which the child and family sit down and eat together, which help to establish better eating practices and monitoring of food intake, has been shown to be associated with better glycaemic outcomes (2), and thus poorer adherence to a healthy diet may be associated with poor parent-child mealtime behaviours (7).

Significant differences were also found in perceived social support. Our data suggest that adolescents with T1DM perceive 
more classmate and teacher's support in comparison with healthy adolescents or adolescents with a long-term illness. The support of diabetes management from teachers and friends seems to be an important factor for adolescents with T1DM in self-management tasks on school days (35). When adolescents perceive that their teachers understand and support diabetes management, they may feel more at ease completing self-management tasks during the school day without worry of being challenged or having to explain themselves (16). Such social relationships might be related to an adolescent's disease adaption or quality of life (36), and reporting high levels of friends' support might be linked with more self-care or better well-being (12). Moreover, our data indicate that adolescents in general perceive high levels of family support, which is partially supported at the national level by the international HBSC study as well (23). Despite this, adolescents with diabetes mellitus feel less support from their parents in comparison with their peers. Similar findings were found in a study by Moore et al. (18), which indicate that the presence of diabetes mellitus has a strong effect on family activities and parents' emotional well-being. Although family support and involvement are important for successful management of T1DM in adolescence, recent studies have found that intrusive, controlling and restrictive behaviour on the part of parents has a negative effect on adolescents' treatment adherence $(2,12,13,15)$. As stressed by Malik and Koot (12), adolescents' experience regarding their parents behaviour may differ not only in regard to the direction and intensity of supportiveness but also to the nature of effect that a specific behaviour may have (12).

This study has several strengths and limitations. The most important strengths of the study are the representativeness of our sample of adolescents and the use of internationally recognized instruments. In addition, our study provides important information with regards to health, eating behaviour and social support in adolescents with T1DM. Nevertheless, some limitations need to be considered. Firstly, all the analyses were based on self-reported data, which is more liable to recall bias, though measures have been in general well-validated (37). Furthermore, questions on sweets and soft drinks do not consider the amount but frequency of use. It seems to be an important issue among adolescents as well (38-40). Finally, our study has a cross-sectional design; therefore, we are unable to formulate conclusive statements about causality.

\section{CONCLUSIONS}

Adolescents with chronic conditions have to face many limitations during their lives. It seems that adolescents with a long-term illness differ from their healthy peers in particular aspects of their health and social environment. Moreover, adolescents with diabetes mellitus differ especially in perceived social support in comparison with healthy peers or adolescents with a long-term illness. Further research and deeper analyses of the impact of social determinants on health might provide useful information to help improve interventions targeting the psychosocial adjustment of these children.

\section{Acknowledgements}

This work was supported by the Slovak Research and Development Agency under contract no. APVV-0032-11 and by the Scientific Grant
Agency of the Ministry of Education, Science, Research and Sport of the Slovak Republic and the Slovak Academy of Sciences, reg. no. 1/0895/14.

\section{Conflict of Interests}

None declared

\section{REFERENCES}

1. Cameron FJ, Wherrett DK. Care of diabetes in children and adolescents controversies, changes, and consensus. Lancet. 2015;385(9982):2096106.

2. Atkinson MA, Eisenbarth GS, Michels AW. Type 1 diabetes. Lancet. 2014;383(9911):69-82.

3. International Diabetes Federation. Global IDF/ISPAD guideline for diabetes in childhood and adolescence. Brussels: International Diabetes Federation; 2011.

4. International Diabetes Federation. IDF diabetes atlas. 7th ed. International Diabetes Federation; 2015

5. Stanik J, Barak L, Klimes I, Gasperikova D, Jancova E, Stanikova D, et al. Diabetes and obesity in children. Bratislava: Univerzita Komenského v Bratislave; 2015. (In Slovak.)

6. National Collaborating Centre for Women's and Children's Health (UK) Diabetes (type 1 and type 2) in children and young people: diagnosis and management. London: National Institute for Health and Care Excellence (UK); 2015.

7. Patton SR. Adherence to diet in youth with type 1 diabetes. J Am Diet Assoc. 2011;111(4):550-5.

8. Nansel TR, Haynie DL, Lipsky LM, Laffel LMB, Mehta SN. Multiple indicators of poor diet quality in children and adolescents with type 1 diabetes are associated with higher Body Mass Index percentile but not glycemic control. J Acad Nutr Diet. 2012;112(11):1728-35.

9. Mehta SN, Volkening LK, Quinn N, Laffel LMB. Intensively managed young children with type 1 diabetes consume high-fat, low-fiber diets similar to age-matched controls. Nutr Res. 2014;34(5):428-35.

10. Clarke WL. Behavioral challenges in the management of childhood diabetes. J Diabetes Sci Technol. 2011;5(2):225-8.

11. Markowitz JT, Volkening LK, Butler DA, Antisdel-Lomaglio J, Anderson BJ, Laffel LMB. Re-examining a measure of diabetes-related burden in parents of young people with Type 1 diabetes: the problem areas in diabetes survey - parent revised version (PAID-PR). Diabet Med. 2012;29(4):526-30.

12. Malik JA, Koot HM. Assessing diabetes support in adolescents: factor structure of the Modified Diabetes Social Support Questionnaire (MDSSQ-Family). Pediatr Diabetes. 2011;12(3 Pt 2):258-65.

13. Delamater AM, de Wit M, McDarby V, Malik J, Acerini CL. ISPAD Clinical Practice Consensus Guidelines 2014. Psychological care of children and adolescents with type 1 diabetes. Pediatr Diabetes. 2014;15 Suppl 20:232-44.

14. Williams C, Sharpe L, Mullan B. Developmental challenges of adolescents with type 1 diabetes: the role of eating attitudes, family support and fear of negative evaluation. Psychol Health Med. 2014;19(3):324-34.

15. Helgeson VS, Palladino DK. Implications of psychosocial factors for diabetes outcomes among children with Type 1 Diabetes: a review. Soc Personal Psychol Compass. 2012;6(3):228-42.

16. Hilliard ME, Harris MA, Weissberg-Benchell J. Diabetes resilience: a model of risk and protection in type 1 diabetes. Curr Diab Rep. 2012;12(6):739-48.

17. Law GU, Walsh J, Queralt V, Nouwen A. Adolescent and parent diabetes distress in type 1 diabetes: The role of self-efficacy, perceived consequences, family responsibility and adolescent-parent discrepancies. J Psychosom Res. 2013;74(4):334-9.

18. Moore SM, Hackworth NJ, Hamilton VE, Northam EP, Cameron FJ. Adolescents with type 1 diabetes: parental perceptions of child health and family functioning and their relationship to adolescent metabolic control. Health Qual Life Outcomes. 2013 Mar 22;11:50. doi: 10.1186/1477-752511-50.

19. Wolfsdorf JI, Garvey KC. Management of diabetes in children. In Jameson JL, De Groot LJ. Endocrinology: adult and pediatric. 7th ed. Philadelphia: W.B. Saunders; 2016. p. 854-82.

20. Tahirović H, Toromanović A, Tahirović E, Begić H, Varni JW. Health-related quality of life and metabolic control in children with type 1 diabetes mellitus in Bosnia and Herzegovina. Coll Antropol. 2012;36(1):117-21. 
21. Ingerski LM, Laffel L, Drotar D, Repaske D, Hood KK. Correlates of glycemic control and quality of life outcomes in adolescents with type 1 diabetes. Pediatr Diabetes. 2010;11(8):563-71.

22. Currie C, Zanotti C, Morgan A, Currie D, de Looze M, Roberts C, et al. editors. Social determinants of health and well-being among young people. Health Behaviour in School-aged Children (HBSC) study: international report from the 2009/10 survey. Health policy for children and adolescents, no. 6. Copenhagen: WHO Regional Office for Europe; 2012.

23. Inchley J, Currie D, Young T, Samdal O, Torsheim T, Augustson L, et al. editors. Growing up unequal: gender and socioeconomic differences in young people's health and well-being. Health Behaviour in School-aged Children (HBSC) study: international report from the 2013/2014 survey. Health policy for children and adolescents, no. 7. Copenhagen: WHO Regional Office for Europe; 2016.

24. Hamrik Z, Bobakova D, Kalman M, Dankulincova Veselska Z, Klein D, Madarasova Geckova A. Physical activity and screen-based activity in healthy development of school-aged children. Cent Eur J Public Health. 2015;23 Suppl:50-6.

25. Blumenthal JA, Burg MM, Barefoot J, Williams RB, Haney T, Zimet G. Social support, type A behavior, and coronary artery disease. Psychosom Med. 1987;49:331-40.

26. Tomcikova Z, Madarasova Geckova A, Orosova O, van Dijk JP, Reijneveld SA. Parental divorce and adolescent drunkenness: role of socioeconomic position, psychological well-being and social support. Eur Addict Res. 2009;15:202-8.

27. Torsheim T, Eriksson L, Schnohr CW, Hansen F, Bjarnason T, Valimaa R. Screen-based activities and physical complaints among adolescents from the Nordic countries. BMC Public Health. 2010 Jun 9;10:324. doi: 10.1186/1471-2458-10-324

28. Mazur J, Sentenac M, Brooks F, Małkowska-Szkutnik A, Gajewski J, Gavin A. Burden of chronic health conditions in adolescence measured by school surveys. Dev Period Med. 2013;17(2):157-64.

29. deWitt M, Delemarre-van de Waal H, Bokma JA, Haasnoot K, Hudijk $\mathrm{MC}$, Gemke RJ, et al. Self-report and parent-report of physical and psychosocial well-being in Dutch adolescents with type 1 diabetes in relation to glycemic control. Health Qual Life Outcomes. 2007 Feb 16;5:10. doi: 10.1186/1477-7525-5-10.

30. Santos T, de Matos MG, Simões MC, Fonseca H, do Céu Machado M. Psychological well-being and chronic condition in Portuguese adolescents. Int J Adolesc Youth. 2015;20(3):334-45.

31. Boogerd EA, Damhuis AM, van Alfen-van der Velden JA, Steeghs MC, Noordam C, et al. Assessment of psychosocial problems in children with type 1 diabetes and their families: the added value of using standardised questionnaires in addition to clinical estimations of nurses and paediatricians. J Clin Nurs. 2015;24(15-16):2143-51.

32. Nieuwesteeg A, Pouwer F, van der Kamp R, van Bakel H, Aanstoot HJ, Hartman E. Quality of life of children with type 1 diabetes: a systematic review. Curr Diabetes Rev. 2012;8(6):434-43.

33. Berntsson L, Berg M, Brydolf M, Hellström AL. Adolescents' experiences of well-being when living with a long-term illness or disability. Scand J Caring Sci. 2007;21(4):419-25.

34. Due P, de Beaufort C, Damsgaard MT, Mortensen HB, Rasmussen M, Ahluwalia N, et al. Do eating behaviors in the general population account for country variance in glycemic control among adolescents with diabetes: the Hvidoere Study Group and the Health Behaviour in School-Aged Children study. Pediatr Diabetes. 2013;14(8):554-61.

35. Hains AA, Berlin KS, Davies WH, Sato AF, Smothers MK, Clifford LC, et al. Attributions of teacher reactions to diabetes self-care behaviors. J Pediatr Psychol. 2009;34(1):97-107.

36. Kakleas K, Kandyla B, Karayianni C, Karavanaki K. Psychosocial problems in adolescents with type 1 diabetes mellitus. Diabetes Metab. 2009;35(5):339-50.

37. Currie C, Inchley J, Molcho M, Lenzi M, Veselska Z, Wild F. Health Behaviour in School-aged Children (HBSC) study protocol: background, methodology and mandatory items for the 2013/14 survey [Internet]. St. Andrews: CAHRU; 2014 [cited 2017 Feb 15]. Available from: http:// www.hbsc.org.

38. Holubcikova J, Kolarcik P, Madarasova Geckova A, Reijneveld SA, van Dijk JP. The mediating effect of daily nervousness and irritability on the relationship between soft drink consumption and aggressive behaviour among adolescents. Int J Public Health. 2015;60(6):699-706.

39. Holubcikova J, Kolarcik P, Madarasova Geckova A, van Dijk JP, Reijneveld SA. Lack of parental rule-setting on eating is associated with a wide range of adolescent unhealthy eating behavior both for boys and girls. BMC Public Health. 2016 Apr 27;16:359. doi: 10.1186/s12889016-3002-4.

40. Duffey KJ, Huybrechts I, Mouratidou T, Libuda L, Kersting M, de Vriendt $\mathrm{T}$, et al. Bevarage consumption among European adolescents in the HELENA study. Eur J Clin Nutr. 2012;66(2):244-52.

Received July 11, 2016

Accepted in revised form October 13, 2016 